\title{
Sustainability in practice: integrated assessment to support policy and decision-making processes
}

\author{
A. Calleros-Islas ${ }^{1} \&$ C. Welsh-Rodriguez ${ }^{2}$ \\ ${ }^{1}$ Institut universitari de recerca en Ciència $i$ Tecnologies de la \\ Sostenibilitat, Universitat Politècnica de Catalunya, Spain \\ ${ }^{2}$ Centro de Ciencias de la Tierra, Universidad Veracruzana, México
}

\begin{abstract}
Sustainability has been recognized, when facing multifaceted decision and policy making processes, as a discipline that broadens the scope under which issues are taken into account. This is considered important given the complex and interrelated challenges faced by societies nowadays. However, it has been found in literature that the sustainable approach still has several obstacles to tackle, from the weakening of its discourse to the lack of real influence and low consensus on its meaning and practice. To reinforce the operational side of sustainability, several methodologies have been designed and implemented over the years with two main shortcomings: an inability to assess sustainability issues as a whole and more specifically, a lack of practical steps that can be included on a day-to-day basis. Integrated assessment emerges as a possible way to summarize the complexity of studying issues from a broader perspective but it is applied in different ways with diverse outcomes that require careful examination. These outcomes are compared by analyzing four integrated assessment tools: life cycle assessment, cost-benefit analysis, stakeholder analysis and multiple scale integrated analysis of societal and ecosystem metabolism. The aim is to observe and determine the degree to which they contribute to the consolidation of the sustainable approach and how they support decision-making processes. It is intended that this exercise help build a diverse yet deep common base for further conversation that will facilitate the process of searching and selecting alternatives to drive socio-ecological systems towards a more sustainable future.

Keywords: sustainable approach, consolidation of sustainability, integrated assessment, policy making, decision-making.
\end{abstract}




\section{Introduction}

Narrowly described as covering present needs without compromising those of the future [1], sustainability has become an important pillar when facing development issues. The present twofold scenario with climate change and scarcity on the environmental side and, conflicts related to inequalities and economic crisis on the socioeconomic one, makes it even more imperative that we consider equity between and within generations in order to achieve more sustainable cycles of human progress [2]. As awareness of resource scarcity grows, tools and methods for determining the best way to use them are needed.

However, there is no one or best way but several ones with different implications and consequences making the task much more complex. Success is not achieved by simply incorporating a sustainable approach into processes where many different interests and goals are at work. Missing still are the practical steps to actually address real issues. Searching for means to integrate sustainability into the processes that lead to real-world actions is necessary so that sustainable principles can drive actions that will result in more consistent decisions, policies and a more balanced development.

\subsection{Measuring sustainability}

Long has been discussed how measurement methodologies contribute to sustainability [3]. Some consider measuring the immeasurable as a way to market natural and social goods and services so that they can be traded like any other product $[4,5]$, while others see that sustainability needs to be evaluated in order to simplify its complexity and generate more accurate assessments $[6,8]$.

While both considerations have pros and cons, sustainability as a discipline still needs to reinforce its operational side. There is a lack of consensus on its definition and practice, showing contradictions between its conceptual and normative conception. The interdisciplinary and diverse conceptualization of sustainability contrasts with its more reductionist practice related to predictive statistics [9]. This contrast has a dual effect: on one hand it gives a broader spectrum for sustainability to be applied in different fields $[10,11]$; while on the other, makes it harder to get reliable, provable results and therefore receive consideration as a scientific approach $[12,13]$.

Methods that are used to assess sustainability issues have different outputs which are the result of different ways of understanding and applying sustainable parameters and principles. Thus, the challenge of dealing with diverse, nonquantifiable and even incomparable variables should be taken into account when evaluating socio-ecological systems [12].

\subsection{Aims and objectives}

The present article analyses four tools to identify how they enable the integrated assessment of sustainability and how they influence decision-making processes.

After beginning with an introduction to sustainability measure, followed by the aims and objectives of the paper, section two briefly presents the 
implemented overall methodology, the selected approach and its justification. Section three overviews the integrated assessment of sustainability and its role in policy design and decision making processes by reviewing four commonly used tools in order to identify how they work and what are the needs and possible pathways to help in the consolidation of the sustainable approach. Section four discusses the results which are then followed up by some conclusions.

\section{Methodology}

Integrated assessment has emerged as a way to account for goods and services usually overlooked by the conventional conception of value. It also considers important aspects of sustainability such as ecological and social justice $[6,14]$ and adds them to the search for efficiency. This approach is based on the value of biodiversity and the other factors that provide services needed for human kind within an ecosystem [15], observing that the real sources of wealth are the biosphere and the social dynamics that occur within it. Therefore, even if they are outside the market, these are the real sources of value [16].

There is a great difficulty in managing something without valuing it first [17]. Before this, as stated by Meadows "we measure what we value, but we also get to value what we measure" [18]. Sustainability assessment can help make people conscious of values invisible to market-oriented economics, considering more than just profit when making daily life decisions that can dictate the pace at which a society develops. It also strengthens social capital, reduces the degree of dependence on the exterior and helps to cope with external forces such as climate change, top-bottom policies or economic crisis [19].

\section{Integrated assessment, policy design and decision-making processes}

The actual state of sustainability assessment is characterized by the existence of several tools and methods carried out by different users with diverse backgrounds and purposes. There are as many sets of sustainability indicators as organisms and research groups that develop and implement those sets [13], showing the low level of commonality that is rooted in the lack of consensus on the very concept of sustainability [20,21].

It should be noted that integrated assessment methods are the function of the adopted vision of sustainability and this determines the kind of policies and actions derived from these methods. Therefore, the degree to which these exercises actually contribute to sustainability depends on the goals and agendas of researchers and their vision of sustainability.

\subsection{Policy and decision-making}

While making decisions, policy makers try to undertake complex issues related to sustainability with certain standards. Meanwhile, governments must negotiate with different actors that have different perceptions of a problem. Along the 
process, the challenge is to find a balance between getting enough support from the parties involved and achieving goals [22].

Decision theory gives three different ways of making decisions according the level of definition and understanding of the process: structured, semi-structured and unstructured [23]. The majority of environmental and social policy decisionmaking processes tend to be unstructured and interrelated. However, they are treated separately by researchers as can be inferred by the methods they implement, in contrast with the broadly accepted socio-ecological system [24]. These are the reasons for studying how integrated assessment can enhance and facilitate decision-making processes, which in turn contributes to catalyze efforts towards sustainability.

\subsection{Methods}

Selected tools, as seen in Figure 1, are in accordance with the three main dimensions of sustainability. Hence it is possible to compare the way in which they actually contribute to the consolidation of sustainability as a whole and to each one of its branches. The focus here is directed on how integrated assessment provides useful information and enhances decision-making and policy design processes as an indicator for strengthening the sustainable approach.

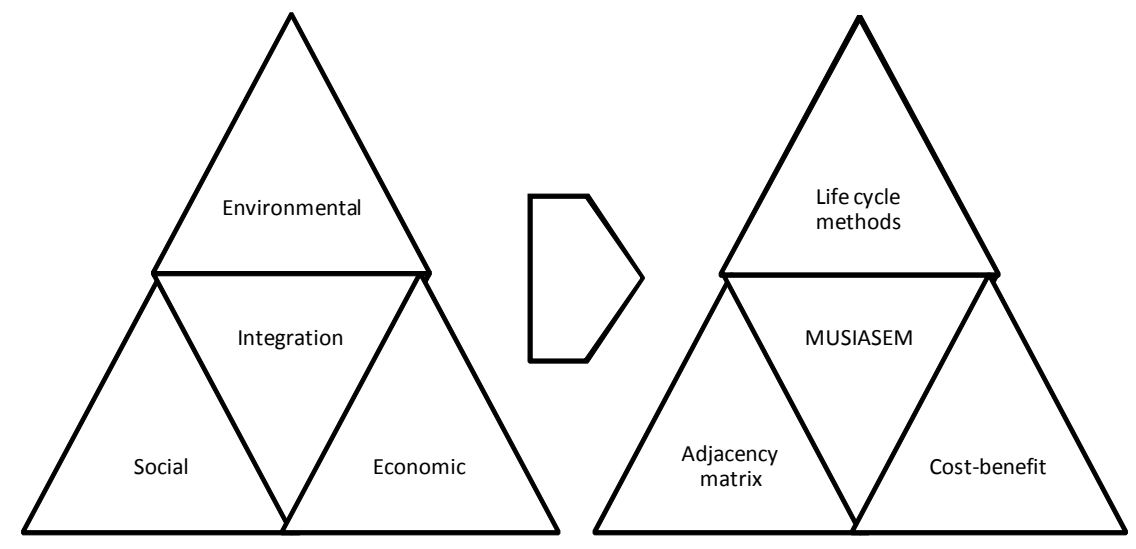

Figure 1: Selected integrated assessment tools.

With many possible options, selected methods may not be the most representative in some aspects, but regarding the objectives of the present paper they were considered as suitable because they allow both quantitative and qualitative analysis. Some have an explicit integrated perspective while others can be implemented in ways that provide a more holistic view.

\subsubsection{Life cycle methodologies}

Over the last 20 years, life cycle methods have become part of the most popular environmental assessment tools for evaluating and describing environmental 
effects caused by products, processes or activities [25]. Life cycle assessment (LCA) is the basic tool among them and it is defined as the analysis of the processes of extraction, use, recovery, emissions and waste generation of a product or service [26]. There are other life cycle methods that complement this scope such as: social life cycle assessment, which includes effects on poverty levels; life cycle costing, accounts the monetary costs or benefits to a defined stakeholder; and life cycle sustainability assessment (LCSA), that analyses the extent to which the life cycle of a product affects the meeting of needs for both present and future generations.

Interest is placed on how life cycle methods can be used to assess sustainability while aiming for simplicity. LCSA is the most adequate method for it focuses on whether a product is sustainable or not in terms of how its life cycle affects the environment, the levels of poverty among current generations and stock changes for future ones [27]. Helps to visualize what the production and consumption model that prevails globally involves. However, it has a high data requirement and has low incidence in policy developing for the difficulty to communicate its results. It is a business-oriented method that focuses on the ecological sphere still lacking a full incorporation of sustainability [28].

\subsubsection{Cost-benefit analysis}

Among the most commonly used economic evaluation tools, the cost-benefit analysis (CBA) focuses on assessing whether a program, policy or a specific investment is financially viable. Therefore, it is useful for determining if benefits can outweigh costs and expresses both the negative as well as the positive effects a certain action can produce in monetary terms [22].

CBA consists of the identification and economic valuation of current and future costs and benefits of a project; determining the rate of discount; time horizon fixation; developing one or more methods to bring the costs and benefits to present values; and estimating the relationship between the costs and benefits $[29,30]$. It uses mechanisms such as grants and subsidies accounting or shadow prices to correct market errors [31]. Usually such studies are used in project evaluation and are typically expressed in terms of the willingness to pay for a specific good or service (consumer preferences).

The major strength of CBA is that it enables the evaluation of different outcomes by translating them into monetary units. Therefore, tangible and intangible, direct and indirect costs and benefits can be assessed in one single analysis. Here is where the integrated character of this instrument is shown.

However, this same strength has been considered the weakest point of CBA. The reason is that by adopting a unidirectional approach with a single criterion assuming all things involved as commensurable, it is impossible to accurately reflect the complexity of interrelated systems, such as socio-ecological systems [32]. The difficulty of measuring and monetizing some aspects can lead to its disregard.

\subsubsection{Stakeholder analysis}

Stakeholder analysis enables the identification of the group or network existing regarding a specific issue, to face multiple interests and goals when making 
decisions or developing policies. It has evolved from its political economy and business management background to include fields such as decision theory, multiple criteria analysis and social participatory approaches [33].

This method helps to understand how a system works while assessing how changes can affect the system. The latter is achieved by the identification of key actors, their interests and perspectives at different levels aiming to understand interactions within development and environmental issues.

One of the methods in stakeholder analysis is the matrix of asymmetric adjacency. It consists on the identification of main social actors within the analyzed socio-ecological system and is based on the perspective provided by the stakeholder according to the intensity and nature of the interaction with other actors. Reflects the nature of relationships between actors represented by assigned values that show the degree of interaction, whether it is positive or negative, etc. Also, ranges are established in terms of the intensity of the interaction between actors and the particular system in the studied area, identifying groups whose decisions and actions directly affect the local ecosystem and that in turn, are affected by how the ecosystem is managed [34].

Stakeholder analysis works as a practical methodology to identify solutions and design policies; it offers a holistic view, can be applied to different subjects and consumes relatively low quantities of time and resources. However, it has some limitations in providing practical answers and does not ensure a strong participation of involved actors [22].

\subsubsection{Multiple scale integrated analysis of societal and ecosystem metabolism (MuSIASEM)}

The MUSIASEM method arises from the concern of information transfer between levels when facing multiple scales and dimensions in complex interrelated issues, where usual quantitative tools are found to fail. It responds to the question of how to assess complexity by adopting a holistic metabolism approach of the socioeconomic and ecological systems [35].

The metabolism of energy and material flows is analyzed following the semantic criterion of fund and flow elements. Fund elements show the characteristics of the system and are to be sustained; flow elements refer to the functions of the system and interact with the studied context.

The strength of MuSIASEM is its integrated nature. It also provides qualitative and quantitative information about the functioning of a system.

Some weaknesses are also to be found. The social dimension is not fully addressed focusing on labor force and household consumption and there is no explicit incorporation of a participatory approach. Second, its descriptive nature makes it difficult to enhance sustainability related decision making and policy design processes. Third and last, it is found to be highly time consuming. It should be stated that these limitations have been partially addressed in a poverty analysis study case [36] and more explicitly by Serrano-Tovar and Giampietro [37] where they propose a multiple source assessment in a rural environment, with a bottom-up approach gathering local data from farmers and a top-down using national statistics. 


\section{Discussion of the results}

The previous analysis has shown that integrated assessment can contribute in different ways to sustainability and give different inputs that can be helpful for decision makers. In this section, results are observed in terms of how the selected methods enhance sustainability and decision making processes.

The selected methods were ranked following the sustainability weak or strong categories (see Table 1) that have been broadly implemented among consulted literature $[8,34,38,40]$. Weak sustainability methods take into account terms and values that follow a standardized view of sustainability due to its translation into monetary terms [4, 40, 41]. Strong sustainability methods are those who adopt a broader scope that approaches to an interdisciplinary and systemic view of nature, society and also the economy [8, 34, 38, 39].

Table 1: Analysis of selected methods in terms of their contribution to consolidate sustainability.

\begin{tabular}{|c|c|c|c|c|}
\hline Method & $\begin{array}{l}\text { Main consulted } \\
\text { authors }\end{array}$ & $\begin{array}{l}\text { Approach / } \\
\text { Case }\end{array}$ & $\begin{array}{l}\text { Contribution to } \\
\text { sustainability }\end{array}$ & $\begin{array}{l}\text { Input for decision } \\
\text { making processes }\end{array}$ \\
\hline $\begin{array}{l}\text { Life cycle } \\
\text { methods }\end{array}$ & $\begin{array}{l}\text { Jones, Rose and Tull } \\
2011 \\
\text { Jørgensen, Herrman \& } \\
\text { Bjørn } 2013 \\
\text { Klöpffer } 1997 \\
\text { Shields et al. } 2011\end{array}$ & $\begin{array}{l}\text { Environmental } \\
\text { engineering \& } \\
\text { assessment; } \\
\text { Policy making. }\end{array}$ & $\begin{array}{l}\text { Medium.- business } \\
\text { oriented; main focus } \\
\text { on the environmental } \\
\text { dimension; lack of } \\
\text { consensus regarding } \\
\text { relation to } \\
\text { sustainability. }\end{array}$ & $\begin{array}{l}\text { Visualization of } \\
\text { production- } \\
\text { consumption model; } \\
\text { internalization of } \\
\text { associated costs; } \\
\text { difficulty to } \\
\text { communicate } \\
\text { results. }\end{array}$ \\
\hline Cost-benefit & $\begin{array}{l}\text { Cordero et al. } 2006 \\
\text { Falconí \& Burbano } 2004 \\
\text { Munda, } 1995 \\
\text { Runhaar, Dieperink \& } \\
\text { Driessen, 2006 }\end{array}$ & $\begin{array}{l}\text { Ecological } \\
\text { Economics; } \\
\text { Watershed case } \\
\text { study. }\end{array}$ & $\begin{array}{l}\text { Weak.- centered on } \\
\text { monetary values; } \\
\text { commensurability } \\
\text { issues. }\end{array}$ & $\begin{array}{l}\text { Useful and clear } \\
\text { results; better if } \\
\text { complemented to } \\
\text { broaden the scope. }\end{array}$ \\
\hline $\begin{array}{l}\text { Stakeholder } \\
\text { analysis }\end{array}$ & $\begin{array}{l}\text { Grimble \& Wellard } 1997 \\
\text { Rescia et al. } 2008 \\
\text { Runhaar, Dieperink \& } \\
\text { Driessen, } 2006\end{array}$ & $\begin{array}{l}\text { Socio-ecological } \\
\text { system; } \\
\text { Decision } \\
\text { making; Rural } \\
\text { landscape case } \\
\text { study. } \\
\end{array}$ & $\begin{array}{l}\text { Strong.- captures } \\
\text { traditional, cultural, } \\
\text { economic and natural } \\
\text { values. }\end{array}$ & $\begin{array}{l}\text { Practical method; } \\
\text { enables } \\
\text { identification of } \\
\text { solutions; offers a } \\
\text { holistic view. }\end{array}$ \\
\hline MuSIASEM & $\begin{array}{l}\text { Giampietro, Mayumi \& } \\
\text { Ramos-Martin } 2009 \\
\text { Madrid, Cabello \& } \\
\text { Giampietro } 2013 \\
\text { Serrano-Tovar \& } \\
\text { Giampietro } 2014\end{array}$ & $\begin{array}{l}\text { Socio-ecological } \\
\text { system; } \\
\text { Complexity; } \\
\text { social } \\
\text { metabolism. }\end{array}$ & $\begin{array}{l}\text { Strong.- provides an } \\
\text { integrated scope; } \\
\text { includes quantitative } \\
\text { and qualitative } \\
\text { information; adaptive } \\
\text { capacity. }\end{array}$ & $\begin{array}{l}\text { Descriptive method; } \\
\text { provides robust } \\
\text { information; holistic } \\
\text { view on how the } \\
\text { system is } \\
\text { functioning. }\end{array}$ \\
\hline
\end{tabular}

Table 1 classifies the four selected methods and main consulted authors, the kind of approach or application of the assessment, followed by the assessed grade of contribution to the consolidation of sustainability and the input for decision making processes that the instrument provides. 
Life cycle methodologies are among the environmental engineering assessment instruments. They are considered to have a medium grade of contribution to sustainability due to their business orientation and focus on environmental impacts. Many other factors than the supply chain are involved [28], however this is partially addressed by LCSA. As for their input to decision making, these methods have relatively low incidence due to the difficulty in communicating their results. Even so, it is a recognized framework for studying the impacts of productive systems on the environment. [28].

CBA is an economic instrument with an ecological economics approach. It is considered to have a weak contribution to sustainability mostly because of the implication of commensurability, implying that environmental or social services and goods can be substituted just like market ones. Notwithstanding its clear results when facing decision making processes, if benefits exceed costs, losses can be easily compensated by other means such as economic payments [31, 42, 43]. CBA is still an important part of integrated assessment due to the ease of communication (everyone understands "money talk") and inputs for scenario building [44]. Researchers state that sustainability-related issues must be assessed by hybridizing different knowledge areas and values [9, 45].

Stakeholder analysis accounts for the socio-ecological system approach and is strongly related to decision making processes. It has a strong contribution to the sustainable approach because it ponders diverse values such as traditional, cultural and natural ones. It also accounts for economic values, but enables the determination of common values and goals $[22,46]$. Social learning tools can be incorporated for more solid outcomes [47, 48].

MuSIASEM has a complex socio-ecological system approach. Its integrated scope provides a strong contribution to sustainability analysis. It includes both quantitative and qualitative data and its adaptive nature gives flexibility to the methodology which in turn suits the nature of sustainability [35, 37, 49]. As for the inputs for decision making, they seem more blurry due to its descriptive character and the much needed experts throughout the analysis. Nevertheless it is important to account that this analytic tool provides an almost exhaustive view of the way a system functions [50].

\section{Conclusions}

More than focusing on a general consensus as normally understood, what is here acknowledged is that efforts must be directed to broaden the scope under which sustainability is implemented. The idea is not to create a best-way to analyze and respond to sustainability related issues, but to build a diverse yet deep network that acts as a common base for further development.

Integrated assessment has been largely implemented as shown in the literature for analyzing sustainability. Each application has a specific knowledge background that determines the kind of approach and the degree of importance given to sustainability. They also generate different inputs for decision making that can be more or less useful for enhancing these processes by communicating results and providing robust information for stakeholders to allow for. 
Especially when related with complex issues that involve multiple scales and dimensions, integrated assessment is key to help decision makers find alternatives. In this sense, examples that are found to have a greater contribution to the sustainable approach provide a broader scope to analyze these alternatives in a systemic way so as to make better informed decisions. Although this can have an impact on the complexity of the decision making processes, it is worth the trade-off in order to be able to achieve more sustainable solutions.

The integration of the sustainable approach is still weak among the reviewed assessment tools. This is shown in the fact that environmental issues dominate over the more intangible social and institutional issues. Efforts are already being made towards this matter as shown by the social life cycle assessment, life cycle sustainability assessment and the execution of cost-benefit analysis as a complimentary device. However, stakeholder analysis and MUSIASEM are the examples that incorporate sustainability in a broader sense among the studied integrated assessment tools and if combined their performance could be even more useful for decision-makers.

\section{Acknowledgements}

The present article is part of a Ph.D. research and was made thanks to the support of the Consejo Nacional de Ciencia y Tecnología (CONACYT), Mexico. Special thanks to the Departament d'Enginyeria Tèxtil i Paperera (UPC) and to the Universidad Veracruzana (UV) for structural and bibliographic resources. We also thank Beatriz Escribano Rodríguez de Robles for her guidance and Jachin Wettstone for his review.

\section{References}

[1] WCDE, Our Common Future, Oxford, 1987.

[2] Biermann, F. et al., Transforming governance and institutions for global sustainability: Key insights from the Earth System Governance Project, Current Opinion in Environmental Sustainability, 4(1), pp. 51-60, 2012.

[3] Krank, S., H. Wallbaum, and A. Grêt-Regamey, Perceived contribution of indicator systems to sustainable development in developing countries, Sustainable Development, 21(1), pp. 18-29, 2013.

[4] Kant, S., Choices of ecosystem capital without discounting and prices, Environmental Monitoring and Assessment, 86(1)-(2), pp. 105-127, 2003.

[5] Salles, J.-M., Valuing biodiversity and ecosystem services: Why put economic values on nature? Comptes Rendus - Biologies, 334(5)-(6), pp. 469-482, 2011.

[6] Costanza, R., Social goals and the valuation of natural capital, Environmental Monitoring and Assessment, 86(1)-(2), pp. 19-28, 2003.

[7] Gómez-Baggethun, E. and R. de Groot, Capital natural y funciones de los ecosistemas: explorando las bases ecológicas de la economía, Revista Ecosistemas, 16(3), 2008. 
[8] Raymond, C. M. et al., Mapping community values for natural capital and ecosystem services, Ecological Economics, 68(5), pp. 1301-1315, 2009.

[9] Benessia, A. et al., Hybridizing sustainability: Towards a new praxis for the present human predicament, Sustainability Science, 7(SUPPL. 1), pp. 75-89, 2012.

[10] CEPAL-ESALC, Evaluación de la Sostenibilidad en América Latina y el Caribe, 2004.

[11] Lang, D. J. et al., Transdisciplinary research in sustainability science: Practice, principles, and challenges, Sustainability Science, 7(SUPPL. 1), pp. 25-43, 2012.

[12] Ekins, P., S. Dresner, and K. Dahlström, The four-capital method of sustainable development evaluation, European Environment, 18(2), pp. 63-80, 2008.

[13] Hak, T., J. Kovanda, and J. Weinzettel, A method to assess the relevance of sustainability indicators: Application to the indicator set of the Czech Republic's Sustainable Development Strategy, Ecological Indicators, 17, pp. 46-57, 2012.

[14] Cornell, S., The rise and rise of ecosystem services: Is "value" the best bridging concept between society and the natural world? In Procedia Environmental Sciences, 2011, 6, pp. 88-95.

[15] Folke, C., Resilience: The emergence of a perspective for social-ecological systems analyses, Global Environmental Change, 16(3), pp. 253-267, 2006.

[16] Cano, M., J. Cendra, and A. Stahel, Oikonomía vs. Crematística: base de las contradicciones del desarrollo moderno, Sostenible? 7, pp. 49-71, 2005.

[17] Liu, S. et al., Valuing ecosystem services: Theory, practice, and the need for a transdisciplinary synthesis, Annals of the New York Academy of Sciences, 1185. pp. 54-78, 2010.

[18] Meadows, D., Indicators \& information systems for sustainable development. A report to the Balaton Group, September 1998.

[19] Sharifi, A. and A. Murayama, A critical review of seven selected neighborhood sustainability assessment tools, Environmental Impact Assessment Review, 38, pp. 73-87, 2013.

[20] Wiek, A. et al., From complex systems analysis to transformational change: A comparative appraisal of sustainability science projects, Sustainability Science, 7(SUPPL. 1), pp. 5-24, 2012.

[21] Salas-Zapata, W. A., L. A. Rios-Osorio, and A. L. Trouchon-Osorio, Typology of scientific reflections needed for sustainability science development, Sustainability Science, pp. 1-6, 2012.

[22] Runhaar, H., C. Dieperink, and P. Driessen, Policy analysis for sustainable development: The toolbox for the environmental social scientist, International Journal of Sustainability in Higher Education, 7(1), pp. 34$56,2006$. 
[23] Liu, K. F. R., Evaluating environmental sustainability: An integration of multiple-criteria decision-making and fuzzy logic, Environmental Management, 39(5), pp. 721-736, 2007.

[24] Hiedanpää, J., A. Jokinen, and P. Jokinen, Making sense of the social: human-nonhuman constellations and the wicked road to sustainability, Sustainability: Science, ..., 8(1), pp. 40-49, 2012.

[25] Shields, D. J., G. A. Blengini, and S. V. Solar, Integrating Life Cycle Assessment and Other Tools for Ex Ante Integrated Sustainability Assessment in the Minerals Industry Politecnico di Torino, Corso Duca degli Abruzzi 24, 10129 Turin, Italy CNR-IGAG, Corso Duca degli Abruzzi 24, 10129 Turin, It, American Journal of Applied Sciences, 8(11), pp. 1214-1227, 2011.

[26] Klöpffer, W., Life cycle assessment: From the beginning to the current state. Environmental science and pollution research international, 4(4), pp. 223-228, 1997.

[27] Jørgensen, A., I. T. Herrmann, and A. Bjørn, Analysis of the link between a definition of sustainability and the life cycle methodologies, International Journal of Life Cycle Assessment, pp. 1-10, 2013.

[28] Jones, S. A., K. Rose, and K. Tull, A Strategic Approach To Improve Environmental Policy-Making For End-Of-Cycle Product Management, Journal of Environmental Assessment Policy and Management, 13(04), pp. 651-672, 2011.

[29] Munda, G., Cost-benefit analysis in integrated environmental assessment: some methodological issues, Ecological Economics, 19(2), pp. 157-168, 1996.

[30] Munda, G., Social multi-criteria evaluation: Methodological foundations and operational consequences, European Journal of Operational Research, 158(3), pp. 662-677, 2004.

[31] Cordero, S. et al., Análisis de costo beneficio de cuatro proyectos hidroeléctricos en la cuenca Changuinola-Teribe. Perú: Alianza para la Conservación y el Desarrollo, 2006.

[32] Falconí, F. and R. Burbano, Instrumentos económicos para la gestión ambiental: decisiones monocriteriales versus decisiones multicriteriales, Revista Iberoamericana De Economía Ecológica, 1, pp. 11-20, 2004.

[33] Grimble, R. and K. Wellard, Stakeholder methodologies in natural resource management: a review of principles, contexts, experiences and opportunities, Agricultural Systems, 55(2), pp. 173-193, 1997.

[34] Rescia, A. J. et al., Reformulating the social-ecological system in a cultural rural mountain landscape in the Picos de Europa region (northern Spain), Landscape and Urban Planning, 88(1), pp. 23-33, 2008.

[35] Madrid, C., V. Cabello, and M. Giampietro, Water-use sustainability in socioecological systems: A multiscale integrated approach, BioScience, 63(1), pp. 14-24, 2013.

[36] Scheidel, A., M. Giampietro, and J. Ramos-Martin, Self-sufficiency or surplus: Conflicting local and national rural development goals in Cambodia, Land Use Policy, 34, pp. 342-352, 2013. 
[37] Serrano-Tovar, T. and M. Giampietro, Multi-scale integrated analysis of rural Laos: Studying metabolic patterns of land uses across different levels and scales, Land Use Policy, 36, pp. 155-170, 2014.

[38] O'Hara, S. U., Valuing socio-diversity, International Journal of Social Economics, 22(5), pp. 31-49, 1995.

[39] Gowdy, J. M., Discounting, hierarchies, and the social aspects of biodiversity protection, International Journal of Social Economics, 23(4)(6), pp. 49-63, 1996.

[40] Cabello, J. M. et al., Multicriteria development of synthetic indicators of the environmental profile of the Spanish regions, Ecological Indicators, 39, pp. 10-23, 2014.

[41] Naredo, J. M., Economía y sostenibilidad. La economía ecológica en perspectiva, Polis, Revista de la Universidad Bolivariana, 1(2), 2001.

[42] Thampapillai, D. J. and S. M. Thangavelu, Towards unitary economics: Valuation of environmental capital for environmental stewardship, International Journal of Social Economics, 31(4), pp. 430-442, 2004.

[43] López Paniagua, C. et al., Demanda, disponibilidad de pago y costo de oportunidad hídrica en la Cuenca Tapalpa, Jalisco, Madera y Bosques, 13(001), pp. 3-23, 2007.

[44] Akhtar, M. K. et al., Integrated assessment model of society-biosphereclimate-economy-energy system, Environmental Modelling \& Software, 49, pp. 1-21, 2013.

[45] Winslow, M. D. et al., Science for improving the monitoring and assessment of dryland degradation, Land Degradation and Development, 22(2), pp. 145-149, 2011.

[46] Mathur, V. N., A. D. F. Price, and S. Austin, Conceptualizing stakeholder engagement in the context of sustainability and its assessment, Construction Management and Economics, 26(6), pp. 601-609, 2008.

[47] Reed, M. S., Stakeholder participation for environmental management: A literature review, Biological Conservation, 141(10), pp. 2417-2431, 2008.

[48] Van der Wal, M. et al., Measuring Social Learning in Participatory Approaches to Natural Resource Management, Environmental Policy and Governance, 24(1), pp. 1-15, 2014.

[49] D'Alisa, G., M. F. Di Nola, and M. Giampietro, A multi-scale analysis of urban waste metabolism: density of waste disposed in Campania, Journal of Cleaner Production, 35, pp. 59-70, 2012.

Ramos-Martín, J. et al., Catalonia's energy metabolism: Using the MuSIASEM approach at different scales, Energy Policy, 37(11), pp. 4658-4671, 2009. 